\title{
Posttraumatic Stress Disorder and Risk for Coronary Heart Disease: A Meta-analytic Review
}

\author{
Donald Edmondson, PhD, MPH, lan M. Kronish, MD, MPH, Jonathan A. Shaffer, PhD, \\ Louise Falzon, PGDiplnf, and Matthew M. Burg, PhD \\ Center for Behavioral Cardiovascular Health, Department of Medicine, Columbia University \\ Medical Center, New York, NY
}

\begin{abstract}
Objective-To estimate the association of posttraumatic stress disorder (PTSD) with risk for incident coronary heart disease (CHD)

Design-Systematic review and meta-analysis

Data sources-Ovid MEDLINE, PsycINFO, Scopus, Cochrane Library, PILOTS database, PubMed Related Articles, and a manual search of reference lists (1948-present)

Study selection-All studies that assessed PTSD in participants initially free of CHD and subsequently assessed CHD/cardiac-specific mortality were included.

Data extraction-Two investigators independently extracted estimates of the association of PTSD to CHD, as well as study characteristics. Odds ratios were converted to hazard ratios (HR), and a random-effects model was used to pool results. A secondary analysis including only studies that reported estimates adjusted for depression was conducted.
\end{abstract}

\footnotetext{
(C) 2013 Mosby, Inc. All rights reserved.

Address for Correspondence: Donald Edmondson, $\mathrm{PhD}, \mathrm{MPH}$, Center for Behavioral Cardiovascular Health, Columbia University Medical Center, 622 W 168 St, PH9-317, New York, NY 10032; dee2109@ columbia.edu; Phone: 212-342-3674; Fax: 212-305-3172.

Author contributions: Dr. Edmondson conceived of the study, led the writing, and is responsible for the statistical analyses. Dr. Kronish assisted with analyses and wrote portions of the manuscript. Dr. Shaffer assisted with analyses and wrote portions of the manuscript. Ms. Falzon served as information specialist, and created and performed the literature search. Dr. Burg served as senior author, abstracted study data, and was involved with all aspects of manuscript preparation.

Permissions: The Corresponding Author has the right to grant on behalf of all authors and does grant on behalf of all authors, an exclusive licence (or non exclusive for government employees) on a worldwide basis to the BMJ Publishing Group Ltd and its Licensees to permit this article (if accepted) to be published in BMJ editions and any other BMJPGL products and sublicences to exploit all subsidiary rights.
}

Financial disclosure: This work was supported by grants HL-088117, HL-084438, and CA-156709 from the National Institutes of Health, Bethesda, MD. Its contents are solely the responsibility of the authors and do not necessarily represent the official view of the National Center for Research Resources or the National Institutes of Health. Supported in part by Columbia University's CTSA grant No. UL1RR024156 from NCATS-NCRR/NIH. Dr. Kronish is supported by grant K23-HL098359 from the National Heart, Lung, and Blood Institute. Dr. Shaffer is supported by grant 12CRP8870004 from the American Heart Association. No funding bodies had any role in study design, data collection and analysis, decision to publish, or preparation of the manuscript.

Competing interests: All authors have completed the ICMJE uniform disclosure form at www.icmje.org/coi_disclosure.pdf and declare: all authors had financial support from NIH for the submitted work; no financial relationships with any organisations that might have an interest in the submitted work in the previous three years; no other relationships or activities that could appear to have influenced the submitted work.

Publisher's Disclaimer: This is a PDF file of an unedited manuscript that has been accepted for publication. As a service to our customers we are providing this early version of the manuscript. The manuscript will undergo copyediting, typesetting, and review of the resulting proof before it is published in its final citable form. Please note that during the production process errors may be discovered which could affect the content, and all legal disclaimers that apply to the journal pertain. 
Results-Six studies met our inclusion criteria (N=402,274); 5 of these included depression as a covariate. The pooled HR for the magnitude of the relationship between PTSD and CHD was 1.55 (95\% CI, 1.34-1.79) before adjustment for depression. The pooled HR estimate for the 5 depression-adjusted estimates $(\mathrm{N}=362,950)$ was 1.27 (95\% CI, 1.08-1.49).

Conclusion-PTSD is independently associated with increased risk for incident CHD, even after adjusting for depression and other covariates. PTSD is common in both military veterans and civilian trauma survivors, and these results suggest that it may be a modifiable risk factor for CHD. Future research should identify mechanisms of this association and determine whether PTSD treatment offsets CHD risk.

Posttraumatic stress disorder (PTSD) is a common, disabling mental health disorder that occurs in individuals who are exposed to traumatic events such as combat, intimate partner violence, or natural disasters. ${ }^{1-3}$ The estimated lifetime prevalence of PTSD in developed nations is $4.4 \%,{ }^{4}$ and ranges from $12.1 \%$ to $30.9 \%$ in military veterans. ${ }^{5-7}$ Individuals with PTSD suffer from a number of disabling symptoms such as intrusive thoughts, nightmares, flashbacks, avoidance of reminders of the traumatic event, and physiological arousal, and are at increased risk for suicide, substance abuse, and inability to work. ${ }^{8}$

Although the profound impact of PTSD on mental health has long been recognized, there has more recently been increasing awareness that individuals with PTSD are at increased risk for physical health impairments, most notably with respect to cardiovascular health. Aside from its association with cardiovascular risk behaviors such as smoking, ${ }^{9}$ alcohol abuse, ${ }^{10}$ and non-adherence to medications, ${ }^{11}$ PTSD has been cross-sectionally associated with hypertension, dyslipidemia, obesity, and diabetes in young veterans of Operations Iraqi Freedom and Enduring Freedom, ${ }^{12}$ and with blood-based measures of endothelial dysfunction ${ }^{13}$ and low-grade systemic inflammation in young civilians. ${ }^{14}$

While recent studies are elucidating associations between PTSD and coronary heart disease (CHD) risk factors, it is less clear whether PTSD is independently associated with incident $\mathrm{CHD}$ and cardiac-specific mortality risk. Accordingly, we used systematic review and metaanalysis to examine the prospective association of PTSD to incident CHD and cardiacspecific mortality. Since PTSD is often comorbid with depression, ${ }^{15}$ a factor shown to increase risk for CHD and mortality, ${ }^{16}$ we additionally adjusted for depression in determining estimates of the association of PTSD to CHD.

\section{Methods}

\section{Sources of funding and author contributions}

This work was supported by grants HL-088117, HL-084438, and CA-156709 from the National Institutes of Health, Bethesda, MD. Its contents are solely the responsibility of the authors and do not necessarily represent the official view of the National Center for Research Resources or the National Institutes of Health. Supported in part by Columbia University's CTSA grant No. UL1RR024156 from NCATS-NCRR/NIH. Dr. Kronish is supported by grant K23-HL098359 from the National Heart, Lung, and Blood Institute. Dr. Shaffer is supported by grant 12CRP8870004 from the American Heart Association and by grant K23HL112850 from the National Institutes of Health, Bethesda, MD. The authors are solely responsible for the design and conduct of this study, all study analyses, the drafting and editing of the paper and its final contents.

\section{Data Sources and Searching}

This research was carried out in accordance with MOOSE guidelines for meta-analyses of observational studies. ${ }^{17}$ Potentially relevant articles were identified by a trained medical 
librarian (L.F.) who searched publicly available computerized databases. Potentially relevant articles were identified by searching the electronic databases Ovid MEDLINE, PsycINFO, Scopus, PILOTS, and the Cochrane Review. Dates searched were from inception to July 2013. The searches were conducted on August 15, 2012 and July 1, 2013. All relevant subject headings and free-text terms were used to represent PTSD and incident CHD/ cardiac-specific mortality, and the sets of terms were combined with AND. Terms for MEDLINE included: exp Stress Disorders, Traumatic/OR ptsd.tw. OR (post-traumatic OR (post adj traumatic)).tw OR posttraumatic.tw. OR acute stress disorder\$.tw. OR asd.tw, exp Acute Coronary Syndrome/OR acute coronary.tw. OR acs.tw OR exp Myocardial Infarction/ OR myocardial infarct\$.tw. OR (mi OR ami).tw. OR (heart adj attack\$).tw. OR (stemi OR nstemi).tw. OR ((preinfarction OR unstable) adj angina $\$$ ).tw. These terms were adapted for the other databases. Additional records were identified by scanning the reference lists of relevant studies and reviews and by employing the Related Articles feature in PubMed, and the Cited Reference Search in ISI Web of Science.

\section{Study Selection}

Eligible study designs included all studies that measured PTSD due to any traumatic event in initially healthy participants and estimated its association with subsequent CHD or cardiac-specific mortality. Two investigators (D.E., M.M.B.) independently reviewed all citations identified through the literature search, using a predefined protocol to assess study eligibility. Articles that clearly did not meet the inclusion criteria were excluded at the title and abstract level. The remaining articles were selected for full text review; articles that did not meet inclusion criteria were excluded. Disagreements regarding the selection of articles were resolved through discussion between the two reviewers, and full consensus was achieved at each stage of review.

\section{Data Extraction}

Two investigators (D.E. and M.M.B.) abstracted information about the dates and cohort sizes of the studies, characteristics of participants enrolled, methods for assessing PTSD, covariates including depression, and the strength of the association between PTSD and incident CHD and cardiac-specific mortality. One study reported estimates for men and women separately, ${ }^{18}$ and we thus extracted data separately from this study. Similarly, one study reported estimates for participants with and without depression separately, ${ }^{19}$ and we extracted data from this study separately as well.

\section{Data Synthesis and Analysis}

Four studies ${ }^{18-21}$ reported the association of PTSD diagnosis or of a positive screen on a validated PTSD self-report screening questionnaire to incident CHD or cardiac mortality. The other two studies ${ }^{22,23}$ reported the risk of incident CHD associated with a 1 standard deviation increase in PTSD symptoms on a self-report PTSD screen questionnaire. For both of those studies we transformed the findings into a single risk estimate, corresponding to two standard deviations above each study's mean as an approximation of a positive PTSD screen - because the sample scores at that level best approximated published cutoffs for the scales used. Further, while half of the studies reported associations in hazard ratios, one study ${ }^{22}$ reported a relative risk and two ${ }^{21,23}$ reported an odds ratio. For this meta-analysis, we calculated an aggregate point estimate as a hazard ratio, using the following equations to convert the relative risk ${ }^{22}$ and odds ratio ${ }^{23}$ to hazard ratios:: $\mathrm{RR}=-$ and $\mathrm{HR}=$ - where RR is the relative risk, OR is the odds ratio, HR is the hazards ratio, and $r$ is the event rate for the reference group (i.e., no PTSD). ${ }^{24,} 25$

Comprehensive MetaAnalysis (version 2, BioStat Software, Engelwood, NJ) was used for completing all statistical tests and associated graphic results. Estimates of the overall risk of 
PTSD with incident CHD were pooled using a random-effects model. A secondary pooled analysis was performed by restricting to the five studies that adjusted for depression as a covariate for the association of PTSD to incident CHD. Heterogeneity assessments using Cochrane's Q statistic and $\mathrm{I}^{2}$ preceded all meta-analytic tests. There was statistically significant heterogeneity, justifying the use of a random-effects model to estimate and test effects. Log-transformed hazard ratios and 95\% confidence intervals (CIs) were calculated for each study using the reported effect size and estimates of the standard error (SE) of each effect drawn from data reported in the article. When articles reported multiple models, we selected the model with the highest level of covariate adjustment. There were too few studies to test for moderator effects however, we provide descriptive information concerning potential moderators below. To address the issue of publication bias, we calculated Orwin's fail-safe $\mathrm{N}$ and created a funnel plot of standard errors by log HRs.

\section{Results}

\section{Literature search}

A comprehensive search resulted in 1194 unique articles, of which 23 qualified for full-text review (Figure 1). Six articles met the final inclusion criteria. There was one disagreement ${ }^{26}$ between the reviewers at the full text stage, which was resolved by discussion and consensus. A second disagreement ${ }^{21}$ occurred at the data extraction stage, because one study published a tightly controlled estimate of the association of PTSD to incident CHD in a sample of twins from a larger registry which could yield an estimate of the association of PTSD to cardiovascular mortality in a larger sample. We decided to include the more precise estimate from the smaller sample, with the recognition that including the estimate from the larger sample may have increased our overall meta-analytic estimate, but would have represented a less rigorous test of our primary study aim.

\section{Study characteristics}

Table 1 gives detailed information about study characteristics, which included 402,274 participants cumulatively. Participants were enrolled between $1982^{23}$ and $2000^{19}$ and were followed for a mean of $2.9^{18}$ to 15 years. ${ }^{20}$ Most participants were military veterans, ${ }^{19-22}$ but many participants were also drawn from the World Trade Center registry of those exposed to the attacks on $9 / 11^{18}$ and from a representative sample of women from East Baltimore exposed to various traumas. ${ }^{23}$ Accordingly, there were diverse types of traumatic experiences represented in the meta-analysis.

PTSD was measured by self-report questionnaire, 18, 20, 22 diagnostic interview, 21,22 or ICD-9 diagnostic codes. ${ }^{19}$ Articles considered a broad range of covariates, from known cardiac risk factors (e.g., systolic blood pressure, hyperlipidemia, smoking) to intelligence scores. Five of the 6 studies included depression as a covariate. ${ }^{19-23}$ Incident CHD and cardiac-specific mortality were assessed by self-report of physician diagnosis, ${ }^{18}, 21,23$ medical records, ${ }^{19,20,22}$ and/or death certificate searches. ${ }^{20,23}$

\section{Association of PTSD with incident CHD and mortality}

There was an indication of heterogeneity in estimates $\left(Q_{5}=10.17 ; P=.07 ; I^{2}=50.83\right)$, with HRs ranging from 1.39 to 3.28. Figure 2 shows the HRs for incident CHD and cardiacspecific mortality associated with PTSD for each of the 6 studies $(\mathrm{N}=402,274)$ with no adjustment for depression. The random-effects model yielded an aggregated HR of 1.55 (95\% CI, 1.34-1.80).

Though difficult to assess with only 5 studies, there was visual but no statistical evidence of publication bias (Figure 3), as the fail-safe N (number of studies with null findings that 
would be needed to conclude that the true hazard ratio was 1) was 210. Orwin's fail-safe N suggested however, that 48 studies with null findings would yield a trivial hazard ratio of less than 1.04 .

\section{Adjustment for depression}

There was also significant heterogeneity in the depression-adjusted estimates $\left(Q_{5}=19.09\right.$, $\left.\mathrm{p}=.002 ; I^{2}=73.81\right)$, thereby supporting the use of a random effects model to pool data. The aggregate HR for the 5 depression-adjusted estimates ${ }^{19-23}(\mathrm{~N}=362,950)$ in a random effects model was 1.27 (95\% CI, 1.08-1.49). All studies that adjusted for depression did so after adjustment for clinical and behavioral CHD risk factors. Depression-adjusted estimates reported in each study, and the method used for assessing depression in each, are given in Table 1.

\section{Descriptive information}

Possible moderators-Although there were not enough studies to test potential moderators of the association of PTSD to incident CHD, we conducted a number of descriptive analyses for likely moderators.

Sex: There appear to be sex differences in risk for PTSD, and there may be a stronger association of PTSD with incident CHD in women. Without adjustment for depression (only one study of women was adjusted for depression), the aggregate HR for the association of PTSD to incident CHD in men was 1.62 (95\% CI, 1.39-1.89), whereas the HR for women was 1.94 (95\% CI, 1.13-3.33). Although underpowered to detect a significant difference, a mixed effects analysis suggested that there may be a sex difference in the association of PTSD to incident CHD $\left(Q_{2}=4.74 ; P=.09\right)$.

Race/ethnicity: Some studies suggest that minority race/ethnicity status is associated with increased risk for PTSD, and there are established racial/ethnic differences in CHD risk. We conducted an exploratory meta-regression analysis to determine whether an association between the racial composition of each study sample and its estimate of the association between PTSD and CHD by coding each study for the proportion of its participants who identified as non-Hispanic White. Studies ranged from $52-100 \%$ non-Hispanic white, but racial composition explained less than $1 \%$ of the variability in effect size estimates, $p=.89$.

Type of PTSD assessment: Meta-analyses of the rate of PTSD due to some types of trauma demonstrate that the method for determining a PTSD "case" (i.e., positive screen on a selfreport questionnaire vs. diagnostic interview) influences the estimate of PTSD prevalence. ${ }^{27-29}$ In the included studies, the HR in those that assessed PTSD by clinical interview was 1.81 (95\% CI, 1.13-2.91) whereas the estimate for those that used screening questionnaires was $1.62(95 \% \mathrm{CI}, 1.42-1.84)$. Although underpowered to detect a significant difference, a mixed effects analysis suggested no difference in the association of PTSD to incident CHD by type of PTSD assessment $\left(Q_{1}=0.21 ; P=.65\right)$.

Date of PTSD assessment: As definitions of both PTSD and CHD have changed over the last 30 years, we tested whether the date of PTSD assessment was associated with studies' effect size estimates using meta-regression. Date of PTSD assessment accounted for only $1 \%$ of the variability in HR estimates, $\mathrm{p}=.50$.

\section{Discussion}

In this first systematic review and meta-analysis of the prospective association of PTSD with incident CHD and cardiac-specific mortality, we found that PTSD is associated with a 55\% 
increase in risk for incident CHD or cardiac-specific mortality after adjustment for numerous demographic, clinical, and psychosocial factors across 6 studies comprising more than 400,000 participants followed for a median of 13 years. After further adjustment for depression, a known contributor to these outcomes, we found that the association between PTSD and CHD was attenuated to $27 \%$, but that risk remained statistically significant.

There are several plausible biological mechanisms linking PTSD with increased CHD risk. PTSD is associated with prolonged reactivity and dysregulation of the autonomic nervous system and hypothalamic-pituitary-adrenal (HPA) axis ${ }^{2}$ which, in turn can contribute to the development and progression of atherosclerosis and cardiovascular system damage. ${ }^{30}$

Neuroendocrine alterations associated with PTSD include increased negative feedback sensitivity of glucocorticoid receptors in the stress-response system and decreased glucocorticoid responsiveness. ${ }^{31-33}$ There is also evidence of autonomic dysfunction in both PTSD and CHD development, as evidenced by decreased heart rate variability, baroreflex dysfunction, and increased QT variability on the electrocardiogram. ${ }^{33}$ Reduced heart rate variability has been shown to predict mortality after MI, ${ }^{34}$ reduced baroreflex sensitivity has been linked with carotid atherosclerosis and increased risk of incident $\mathrm{CHD},{ }^{33}$ and increased QT variability is a predictor of sudden cardiac death. ${ }^{35}$ Further, von Känel and colleagues $^{14,36}$ found a dose-response relationship between PTSD and inflammatory biomarkers such that as severity of PTSD symptoms increase, levels of TNF- $\alpha$ and IL-1 $\beta$ increase and levels of IL-4 decrease. This is an important finding, as CHD is understood to be a disease of inflammation ${ }^{37}$ and the inflammatory markers observed to be dysregulated in PTSD have been linked to CHD events ${ }^{38}$ (32). Finally, Ahmadi and colleagues ${ }^{26}$ recently reported a dose-response relationship between PTSD and coronary artery calcium (CAC), a marker of atherosclerosis, and found that the association between PTSD and all-cause mortality was strongest at high levels of CAC.

Since depression is an established risk factor for CHD and often comorbid with PTSD, the finding that the association of PTSD with CHD is independent of depression is important. Depression was assessed by self-report, ${ }^{22}$ interview, ${ }^{21,23}$ and chart review ${ }^{18,20}$ in the included studies, but only one of the studies reported the association of depression (by ICD-9 code) and incident CHD (HR=1.39; 95\% CI=1.34-1.45). ${ }^{18}$ The same study reported significant associations between ICD-9 code for other anxiety disorders and incident CHD, including panic disorder $(\mathrm{HR}=1.53 ; 95 \% \mathrm{CI}=1.36-1.71)$, generalized anxiety disorder $(\mathrm{HR}=1.28 ; 95 \% \mathrm{CI}=1.18-1.38)$, and anxiety disorder unspecified $(\mathrm{HR}=1.44 ; 95 \% \mathrm{CI}=1.37$ 1.53). These associations are important because PTSD is often comorbid with a host of psychiatric disorders ${ }^{15}$ and to the extent that many are associated with incident CHD (and CHD risk factors), ${ }^{16,27,39}$ isolating the unique contribution of PTSD from a broader constellation of - distress is necessary. ${ }^{40}$ The strongest evidence to date that the association of PTSD to incident CHD is independent of general distress is a recent study by Vaccarino et al., ${ }^{21}$ in which it was found that adjustment for depression and other psychiatric diagnoses did not diminish the PTSD-CHD association. Further, in that study, CHD risk was no different for participants with comorbid PTSD and depression than for those with PTSD alone. Future studies that focus on the unique association of PTSD with CHD mechanisms will be important.

\section{Outstanding issues}

Numerous behavioral mechanisms may link PTSD with increased risk of CHD and cardiacspecific mortality. PTSD has been associated with smoking, ${ }^{41}$ drug and alcohol abuse, $, 3,10$ and obesity. ${ }^{42}$ Most of the included studies adjusted for one or more of these behavioral variables when estimating the association of PTSD to incident CHD. None of the included studies however, directly tested whether these health behavior variables-which may be on the pathway from PTSD to CHD—are mediators of the association. The recent study by 
Vaccarino et $\mathrm{al}^{21}$ showed that, at least in twins who are male Vietnam veterans, the association of PTSD with important CHD health behaviors accounted for almost none of the association of PTSD to incident CHD. That PTSD remained associated with CHD suggests that biological factors may play an important role in the association between PTSD and incident CHD. Of note, we have shown that PTSD is associated with non-adherence to prescribed medications in various patient populations. ${ }^{11,43,44}$. Hence, adherence to cardiovascular medications should also be tested as a potentially important behavioral mediator of the association between PTSD and CHD.

A second outstanding issue is whether sex modifies the association of PTSD to CHD. There are known sex differences in the incidence and presentation of $\mathrm{CHD}^{45}$ and PTSD ${ }^{46}$ so it stands to reason that the link between the two may be modified by sex as well. Given the small number of studies to address the PTSD-CHD link, and the myriad differences between the populations sampled that were unrelated to sex, we could only describe the slightly stronger effect size estimate for women in these studies. The one included study that tested the association of PTSD with CHD risk separately for men and women ${ }^{18}$ did not show sex differences, but it also failed to control for depression - a CHD risk factor with substantial sex differences. Our descriptive analysis suggested that the risk for CHD associated with PTSD in women may be greater than in men. Future research should take up this question rigorously.

A third issue is whether minority race and/or ethnicity modifies the association of PTSD to incident CHD. Although our survey of the research to date showed no evidence of race/ ethnicity differences in the PTSD-CHD association, the lack of racial and ethnic diversity both across and within studies highlights the need for future research in this area.

Another issue that is not quite resolved is whether PTSD itself, or the experience of trauma more generally, is responsible for the CHD risk that is reported to be associated with PTSD. ${ }^{47}$ This meta-analysis suggests that PTSD is the primary culprit, as in the two included studies to address the issue found that PTSD—and not high combat exposure-was associated with incident CHD. ${ }^{20,21}$ Several studies have measured associations between trauma exposure and/or PTSD and physical health. Combat exposure has been associated with poor health and mortality in World War II veterans ${ }^{48}$ and incident arterial disease 49 and self-reported physical health problems, ${ }^{50}$ in combat veterans. One large study with 20 years of follow-up however, found no association between combat exposure and selfreported physical health. ${ }^{51}$ In contrast, PTSD has been consistently and independently associated with a near doubling of risk for all-cause and cardiovascular mortality. ${ }^{52}$ Further, although some studies have shown unique effects of both combat exposure and PTSD on health, ${ }^{53}$ severity of PTSD symptoms often explains associations between trauma exposure and new onset of disease or health complaints in studies that have considered both simultaneously. $49,54,55$

Whether a full diagnosis of PTSD—versus a continuous measure of PTSD symptoms assessed by self-report questionnaire-- is best for estimating CHD risk is a question currently being considered. The studies included in this meta-analysis suggest that there is a doseresponse association of PTSD symptoms reported on self-report screening instruments and incident CHD risk..$^{21-23}$ These findings agree with studies of PTSD after CHD events, ${ }^{27,28,56}$ which have shown a similar dose-response association of PTSD with recurrent CHD. ${ }^{57}$

\section{Limitations}

This study should be interpreted in light of its limitations. First, because we did not include unpublished articles or articles from non-peer-reviewed journals, we may have excluded 
negative findings. ${ }^{58}$ Second, although some articles included in this review were from samples large enough to report useful data on within-sex, race, or ethnicity estimates, there were not enough studies to conduct appropriately powered moderator or meta-regression analyses to determine whether our aggregate estimate was significantly influenced by participant or study characteristics. Third, we only reviewed studies that included measurements of PTSD at one time point and its association with a new onset of a CHD diagnosis or mortality, though some of the studies were prospective and some were based on retrospective data review of administrative databases. Other studies that we did not include in this review have found associations of PTSD with incident CHD using study designs that do not permit conclusions about the temporal relationship between the two, ${ }^{59-62}$ or prospective associations of PTSD with other manifestations of cardiovascular disease. ${ }^{63}$ Establishing the temporal relationship between PTSD and CHD is important because cardiac events have been shown to cause PTSD in CHD patients. ${ }^{28,56}$ Finally, all of the included studies were from the U.S., so the generalizability of the findings outside the U.S. cannot be determined.

\section{Implications and Conclusions}

This systematic review and meta-analysis provides compelling evidence from 6 studies comprising over 400,000 participants that PTSD is associated with risk for incident CHD and cardiac mortality. Further, it suggests that the association of PTSD to cardiac events and mortality is independent of depression. Many questions concerning the association of PTSD to incident CHD remain open, and more research is needed to determine the precise nature and mechanisms of the association, and which populations are at greatest risk. Although questions remain, clinicians should be aware of the cardiovascular implications of PTSD. There is evidence that the likely mechanisms by which PTSD carries cardiovascular risk can be identified early after the PTSD-inducing trauma, and that they may accumulate over many years before an acute cardiac event.

PTSD represents a major quality of life burden, and as such should be treated. If PTSD symptoms do not remit, clinicians may still be able to alter the CHD risk trajectory. Unlike many other psychiatric disorders, targeted screening for PTSD is possible since the traumatic events that cause it are identifiable, and screening may allow for early cardiovascular disease risk stratification, particularly once the mechanisms underlying the association of PTSD to cardiac events can be identified. Future research should focus on identifying plausible mechanisms, establishing the feasibility, efficacy, and costs of screening for and tracking CHD risk factors among individuals with PTSD, and determine whether PTSD treatment can offset risk for cardiac events and mortality.

\section{Acknowledgments}

Funding: This work was supported by grants HL-088117, HL-084438, and CA-156709 from the National Institutes of Health, Bethesda, MD. Its contents are solely the responsibility of the authors and do not necessarily represent the official view of the National Center for Research Resources or the National Institutes of Health. Supported in part by Columbia University's CTSA grant No. UL1RR024156 from NCATS-NCRR/NIH. Dr. Kronish is supported by grant K23-HL098359 from the National Heart, Lung, and Blood Institute. Dr. Shaffer is supported by grant 12CRP8870004 from the American Heart Association and by grant K23HL112850 from the National Institutes of Health, Bethesda, MD. No funding bodies had any role in study design, data collection and analysis, decision to publish, or preparation of the manuscript.

\section{References}

1. Boscarino JA. PTSD is a risk factor for cardiovascular disease: Time for increased screening and clinical intervention. Preventive medicine. 2012 
2. Boscarino JA. Post-Traumatic Stress Disorder and Cardiovascular Disease Link: Time to Identify Specific Pathways and Interventions. Am J Cardiol. 2011; 108(7):1052-1053. [PubMed: 21920186]

3. Sullivan T, Cavanaugh C, Buckner J, Edmondson D. Testing posttraumatic stress as a mediator of physical, sexual, and psychological intimate partner violence and substance problems among women. Journal of traumatic stress. 2009; 22(6):575-584. [PubMed: 19960546]

4. Kessler RC, Ormel J, Petukhova M, McLaughlin KA, Green JG, Russo LJ, et al. Development of lifetime comorbidity in the World Health Organization world mental health surveys. Archives of general psychiatry. 2011; 68(1):90. [PubMed: 21199968]

5. Kang HK, Natelson BH, Mahan CM, Lee KY, Murphy FM. Post-traumatic stress disorder and chronic fatigue syndrome-like illness among Gulf War veterans: a population-based survey of 30,000 veterans. American journal of epidemiology. 2003; 157(2):141-148. [PubMed: 12522021]

6. Kulka, RA.; Schlenger, WE.; Fairbank, JA.; Hough, RL.; Jordan, BK.; Marmar, CR., et al. Trauma and the Vietnam war generation: Report of findings from the National Vietnam Veterans Readjustment Study. Brunner/Mazel; 1990.

7. Tanielian, T.; Jaycox, L. Invisible wounds of war: Psychological and cognitive injuries, their consequences, and services to assist recovery. Rand Corp; 2008.

8. Yehuda R. Post-traumatic stress disorder. N Engl J Med. 2002; 346(2):108-14. [PubMed: 11784878]

9. Fu SS, McFall M, Saxon AJ, Beckham JC, Carmody TP, Baker DG, et al. Post-traumatic stress disorder and smoking: a systematic review. Nicotine \& tobacco research. 2007; 9(11):1071-1084. [PubMed: 17978982]

10. McFarlane AC. Epidemiological evidence about the relationship between ptsd and alcohol abuse:: The nature of the association. Addictive Behaviors. 1998; 23(6):813-825. [PubMed: 9801718]

11. Kronish IM, Edmondson D, Li Y, Cohen BE. Post-traumatic stress disorder and medication adherence: results from the Mind Your Heart study. J Psychiatr Res. 2012; 46(12):1595-9. [PubMed: 22809686]

12. Cohen BE, Marmar C, Ren L, Bertenthal D, Seal KH. Association of cardiovascular risk factors with mental health diagnoses in Iraq and Afghanistan war veterans using VA health care. JAMA: The Journal of the American Medical Association. 2009; 302(5):489-492. [PubMed: 19654382]

13. von Känel R, Hepp U, Traber R, Kraemer B, Mica L, Keel M, et al. Measures of endothelial dysfunction in plasma of patients with posttraumatic stress disorder. Psychiatry Res. 2008; 158(3): 363-373. [PubMed: 18252265]

14. von Känel R, Hepp U, Kraemer B, Traber R, Keel M, Mica L, et al. Evidence for low-grade systemic proinflammatory activity in patients with posttraumatic stress disorder. Journal of Psychiatric Research. 2007; 41(9):744-752. [PubMed: 16901505]

15. O'Donnell M, Creamer M, Pattison P. Posttraumatic stress disorder and depression following trauma: Understanding comorbidity. American Journal of Psychiatry. 2004; 161(8):1390. [PubMed: 15285964]

16. Van der Kooy K, Van Hout H, Marwijk H, Marten H, Stehouwer C, Beekman A. Depression and the risk for cardiovascular diseases: systematic review and meta analysis. Int J Geriatr Psychiatry. 2007; 22(7):613-626. [PubMed: 17236251]

17. Stroup DF, Berlin JA, Morton SC, Olkin I, Williamson GD, Rennie D, et al. Meta-analysis of observational studies in epidemiology: a proposal for reporting. Meta-analysis Of Observational Studies in Epidemiology (MOOSE) group. Jama. 2000; 283(15):2008-12. [PubMed: 10789670]

18. Jordan HT, Miller-Archie SA, Cone JE, Morabia A, Stellman SD. Heart disease among adults exposed to the September 11, 2001 World Trade Center disaster: results from the World Trade Center Health Registry. Preventive medicine. 2011; 53(6):370-6. [PubMed: 22040652]

19. Scherrer JF, Chrusciel T, Zeringue A, Garfield LD, Hauptman PJ, Lustman PJ, et al. Anxiety disorders increase risk for incident myocardial infarction in depressed and nondepressed Veterans Administration patients. Am Heart J. 2010; 159(5):772-779. [PubMed: 20435185]

20. Boscarino J. A prospective study of PTSD and early-age heart disease mortality among Vietnam veterans: implications for surveillance and prevention. Psychosomatic Medicine. 2008; 70(6):668. [PubMed: 18596248] 
21. Vaccarino V, Goldberg J, Rooks C, Shah AJ, Veledar E, Faber TL, et al. Posttraumatic Stress Disorder and Incidence of Coronary Heart Disease: A Twin Study. Journal of the American College of Cardiology. 2013

22. Kubzansky L, Koenen K, Spiro A III, Vokonas P, Sparrow D. Prospective study of posttraumatic stress disorder symptoms and coronary heart disease in the Normative Aging Study. Archives of general psychiatry. 2007; 64(1):109. [PubMed: 17199060]

23. Kubzansky LD, Koenen KC, Jones C, Eaton WW. A prospective study of posttraumatic stress disorder symptoms and coronary heart disease in women. Health Psychology. 2009; 28(1):125130. [PubMed: 19210026]

24. Zhang JYKF. What's the relative risk?: A method of correcting the odds ratio in cohort studies of common outcomes. JAMA: The Journal of the American Medical Association. 1998; 280(19): 1690-1691. [PubMed: 9832001]

25. Roelfs DJ, Shor E, Davidson KW, Schwartz JE. Losing life and livelihood: A systematic review and meta-analysis of unemployment and all-cause mortality. Social Science \& Medicine. 2011; 72(6):840-854. [PubMed: 21330027]

26. Ahmadi N, Hajsadeghi F, Mirshkarlo HB, Budoff M, Yehuda R, Ebrahimi R. Post-traumatic stress disorder, coronary atherosclerosis, and mortality. Am J Cardiol. 2011; 108(1):29-33. [PubMed: 21530936]

27. Edmondson D, Cohen BE. Posttraumatic stress disorder and cardiovascular disease. Prog Cardiovasc Dis. 2013; 55(6):548-56. [PubMed: 23621964]

28. Edmondson D, Richardson S, Falzon L, Davidson KW, Mills MA, Neria Y. Posttraumatic stress disorder prevalence and risk of recurrence in acute coronary syndrome patients: A meta-analytic review. PLoS ONE. 2012; 7(6):e38915. [PubMed: 22745687]

29. Edmondson D, Richardson S, Fausett JK, Falzon L, Howard VJ, Kronish IM. Prevalence of PTSD in Survivors of Stroke and Transient Ischemic Attack: A Meta-Analytic Review. PLOS ONE. 2013; 8(6):e66435. [PubMed: 23840467]

30. McEwen BS. Mood disorders and allostatic load. Biological Psychiatry. 2003; 54(3):200-207. [PubMed: 12893096]

31. Yehuda R. Advances in understanding neuroendocrine alterations in PTSD and their therapeutic implications. Ann N Y Acad Sci. 2006; 1071:137-66. [PubMed: 16891568]

32. VanItallie TB. Stress: a risk factor for serious illness. Metabolism-Clinical and Experimental. 2002; 51(1):40-45. [PubMed: 12040540]

33. Rozanski A, Blumenthal JA, Davidson KW, Saab PG, Kubzansky L. The epidemiology, pathophysiology, and management of psychosocial risk factors in cardiac practice:: The emerging field of behavioral cardiology. Journal of the American College of Cardiology. 2005; 45(5):637651. [PubMed: 15734605]

34. Bigger JT Jr, Fleiss JL, Steinman RC, Rolnitzky LM, Kleiger RE, Rottman JN. Frequency domain measures of heart period variability and mortality after myocardial infarction. Circulation. 1992; 85(1):164-171. [PubMed: 1728446]

35. Piccirillo G, Magrì D, Matera S, Magnanti M, Torrini A, Pasquazzi E, et al. QT variability strongly predicts sudden cardiac death in asymptomatic subjects with mild or moderate left ventricular systolic dysfunction: a prospective study. European heart journal. 2007; 28(11):1344-1350. [PubMed: 17101636]

36. von Kanel R, Begre S, Abbas CC, Saner H, Gander M-L, Schmid J-P. Inflammatory biomarkers in patients with posttraumatic stress disorder caused by myocardial infarction and the role of depressive symptoms. Neuroimmunomodulation. 2010; 17(1):39-46. [PubMed: 19816056]

37. Libby P, Ridker PM, Hansson GK. Inflammation in Atherosclerosis:: From Pathophysiology to Practice. Journal of the American College of Cardiology. 2009; 54(23):2129-2138. [PubMed: 19942084]

38. Kaptoge S, Di Angelantonio E, Lowe G, Pepys MB, Thompson SG, Collins R, et al. C-reactive protein concentration and risk of coronary heart disease, stroke, and mortality: an individual participant meta-analysis. Lancet. 2010; 375(9709):132. [PubMed: 20031199]

39. Edmondson D, Davidson KW. Symposium on psychosocial factors in cardiovascular disease. Introduction Prog Cardiovasc Dis. 2013; 55(6):509-10. 
40. Richardson S, Shaffer JA, Falzon L, Krupka D, Davidson KW, Edmondson D. Meta-analysis of perceived stress and its association with incident coronary heart disease. Am J Cardiol. 2012; 110(12):1711-6. [PubMed: 22975465]

41. Hapke U, Schumann A, Rumpf HJ, John U, Konerding U, Meyer C. Association of smoking and nicotine dependence with trauma and posttraumatic stress disorder in a general population sample. The Journal of Nervous and Mental Disease. 2005; 193(12):843-846. [PubMed: 16319709]

42. Vieweg W, Julius D, Bates J, Quinn J III, Fernandez A, Hasnain M, et al. Posttraumatic stress disorder as a risk factor for obesity among male military veterans. Acta Psychiatrica Scandinavica. 2007; 116(6):483-487. [PubMed: 17997727]

43. Kronish IM, Edmondson D, Goldfinger JZ, Fei K, Horowitz CR. Posttraumatic stress disorder and adherence to medications in survivors of strokes and transient ischemic attacks. Stroke. 2012; 43(8):2192-7. [PubMed: 22618380]

44. Shemesh E, Yehuda R, Milo O, Dinur I, Rudnick A, Vered Z, et al. Posttraumatic stress, nonadherence, and adverse outcome in survivors of a myocardial infarction. Psychosomatic Medicine. 2004; 66(4):521-6. [PubMed: 15272097]

45. Roger VL, Go AS, Lloyd-Jones DM, Benjamin EJ, Berry JD, Borden WB, et al. Heart Disease and Stroke Statistics-2012 Update A Report From the American Heart Association. Circulation. 2012; 125(1):e2-e220. [PubMed: 22179539]

46. Breslau NDGCAPPELSLR. SEx differences in posttraumatic stress disorder. Archives of General Psychiatry. 1997; 54(11):1044-1048. [PubMed: 9366662]

47. O'Toole BI, Catts SV. Trauma, PTSD, and physical health: An epidemiological study of Australian Vietnam veterans. Journal of Psychosomatic Research. 2008; 64(1):33-40. [PubMed: 18157997]

48. Elder GH Jr, Shanahan MJ, Clipp EC. Linking combat and physical health: The legacy of World War II in men's lives. The American Journal of Psychiatry; The American Journal of Psychiatry. 1997

49. Schnurr PP, Spiro A, Paris A. Physician-diagnosed medical disorders in relation to PTSD symptoms in older male military veterans. Health Psychology. 2000; 19(1):91-97. [PubMed: 10711592]

50. Wolfe J, Proctor SP, Erickson DJ, Heeren T, Friedman MJ, Huang MT, et al. Relationship of Psychiatric Status to Gulf War Veterans' Health Problems. Psychosomatic Medicine. 1999; 61(4): 532-540. [PubMed: 10443762]

51. Decouflé P, Holmgreen P, Boyie CA, Stroup NE. Self-reported Health Status of Vietnam Veterans in Relation to Perceived Exposure to Herbicides and Combat. American journal of epidemiology. 1992; 135(3):312-323. [PubMed: 1546707]

52. Boscarino J. Posttraumatic stress disorder and mortality among US Army veterans 30 years after military service. Annals of epidemiology. 2006; 16(4):248-256. [PubMed: 16099672]

53. Schnurr PP, Spiro A. Combat exposure, posttraumatic stress disorder symptoms, and health behaviors as predictors of self-reported physical health in older veterans. The Journal of Nervous and Mental Disease. 1999; 187(6):353. [PubMed: 10379722]

54. Wolfe J, Proctor SP, Erickson DJ, Heeren T, Friedman MJ, Huang MT, et al. Relationship of Psychiatric Status to Gulf War Veterans' Health Problems. Psychosomatic Medicine. 1999; 61(4): 532-540. [PubMed: 10443762]

55. Taft CT, Stern AS, King LA, King DW. Modeling physical health and functional health status: The role of combat exposure, posttraumatic stress disorder, and personal resource attributes. Journal of traumatic stress. 1999; 12(1):3-23. [PubMed: 10027139]

56. Edmondson D, Rieckmann N, Shaffer JA, Schwartz JE, Burg MM, Davidson KW, et al. Posttraumatic stress due to an acute coronary syndrome increases risk of 42-month major adverse cardiac events and all-cause mortality. J Psychiatr Res. 2011; 45(12):1621-6. [PubMed: 21807378]

57. von Känel R, Hari R, Schmid JP, Wiedemar L, Guler E, Barth J, et al. Non-fatal cardiovascular outcome in patients with posttraumatic stress symptoms caused by myocardial infarction. Journal of cardiology. 2011; 58(1):61-68. [PubMed: 21493042] 
58. Egger, M.; Davey Smith, G.; Altman, DG., editors. Systematic reviews in health care: Metaanalysis in context. London: BMJ Books; 2001.

59. Spitzer C, Barnow S, Völzke H, John U, Freyberger HJ, Grabe HJ. Trauma, posttraumatic stress disorder, and physical illness: findings from the general population. Psychosomatic Medicine. 2009; 71(9):1012-1017. [PubMed: 19834051]

60. Dobie DJ, Kivlahan DR, Maynard C, Bush KR, Davis TM, Bradley KA. Posttraumatic stress disorder in female veterans: association with self-reported health problems and functional impairment. Archives of internal medicine. 2004; 164(4):394. [PubMed: 14980990]

61. Schnurr P, Spiro A, Paris A. Physician-diagnosed medical disorders in relation to PTSD symptoms in older male military veterans. Health Psychology. 2000; 19(1):91-97. [PubMed: 10711592]

62. Kang HK, Bullman TA, Taylor JW. Risk of selected cardiovascular diseases and posttraumatic stress disorder among former World War II prisoners of war. Annals of epidemiology. 2006; 16(5):381-386. [PubMed: 15994096]

63. Dirkzwager AJ, van der Velden PG, Grievink L, Yzermans CJ. Disaster-related posttraumatic stress disorder and physical health. Psychosomatic medicine. 2007; 69(5):435-440. [PubMed: 17556645] 


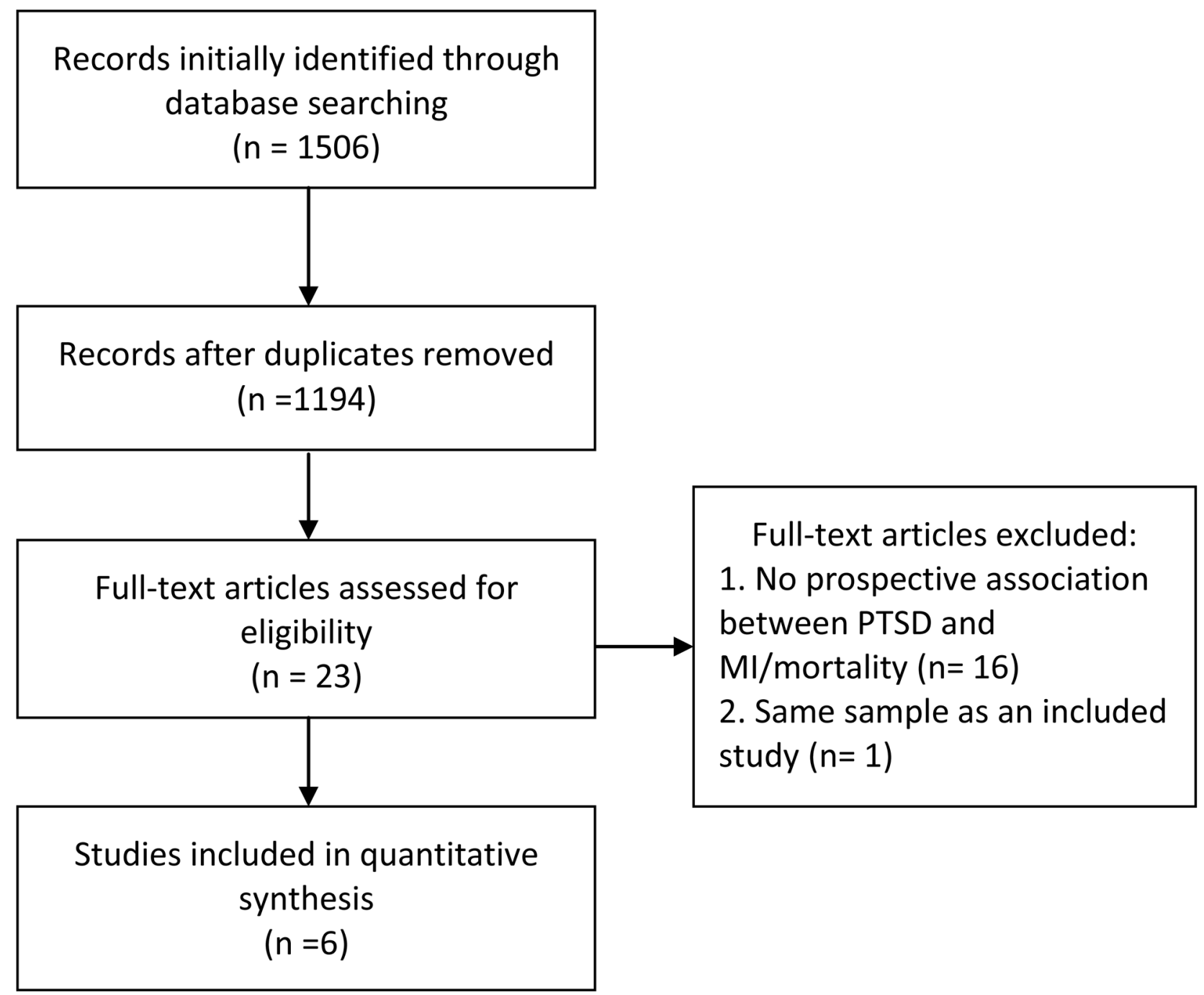

Figure 1.

Search strategy flowchart 


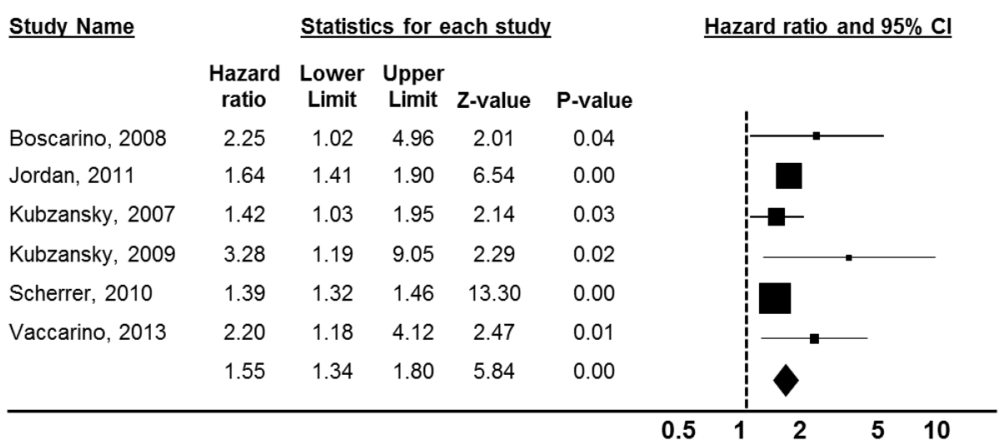

Figure 2.

Forest plot of the association of PTSD to incident CHD

Note: The area of each square is proportional to the study's weight in the meta-analysis, and each line represents the confidence interval around the estimate. The diamond represents the aggregate estimate, and its lateral points indicate confidence intervals for this estimate. 




Figure 3.

Funnel plot to assess publication bias across studies 


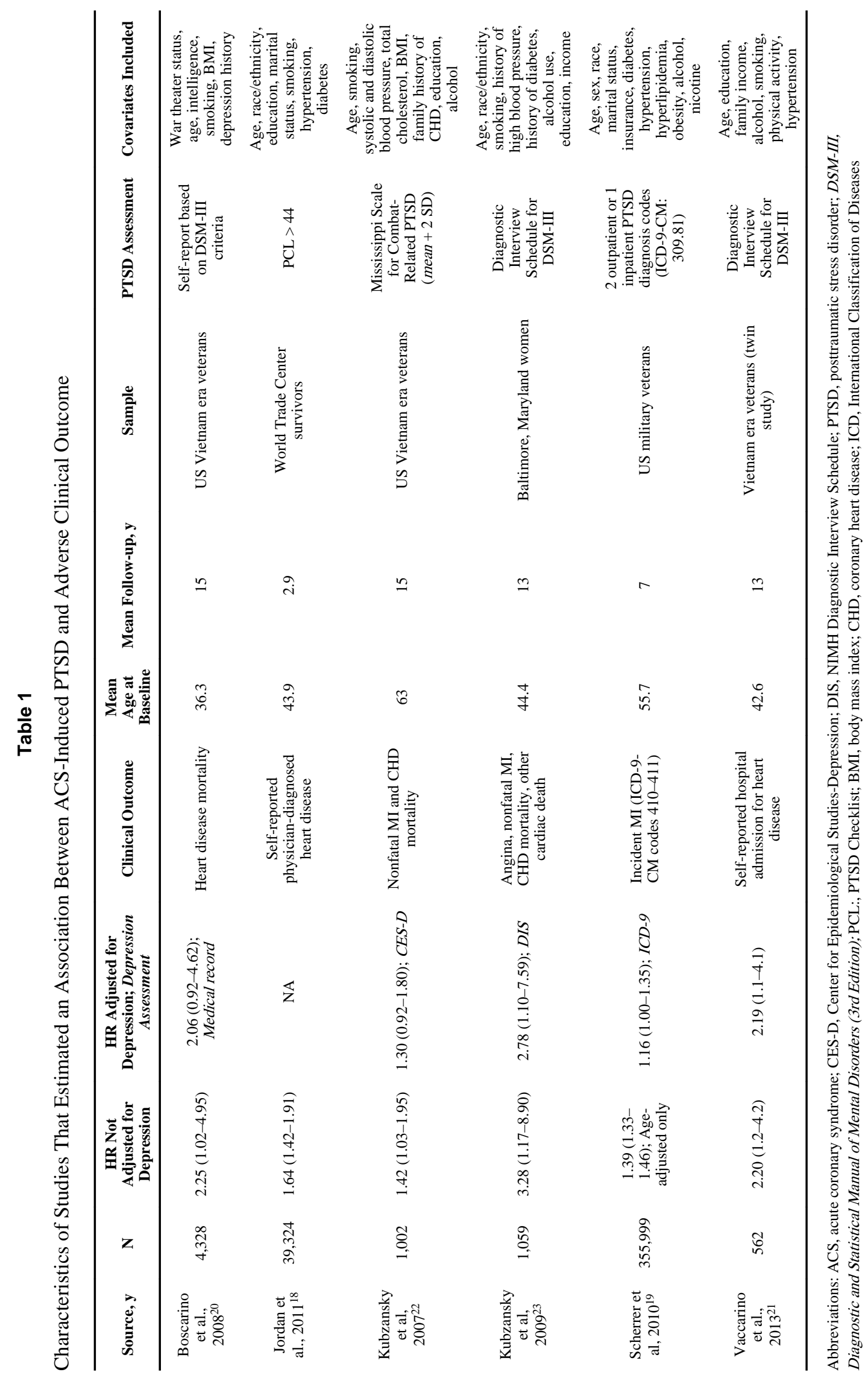
Am Heart J. Author manuscript; available in PMC 2014 November 01. 